\title{
Voz e saúde vocal do tradutor e intérprete oral: estudo de revisão
}

\section{Voice and vocal health of oral translator and interpreting: a review study}

RESUmo Os tradutores e/ou intérpretes orais necessitam ter uma voz de qualidade em seu trabalho; e as suas altas demandas de uso vocal profissional requerem atenção e cuidados. O objetivo do artigo é compreender o que a literatura trata a respeito da voz do tradutor e intérprete oral. Para isso, é realizada uma revisão sistemática da literatura, com buscas on-linenas bases: Lilacs, Scielo, DOAJ, Medline, ScienceDirect, SpringerLink e Wiley Online Library e anais de congressos de Fonoaudiologia e de Tradução e Interpretação. A seleção envolveu critérios e processos de inclusões e exclusões e resultou em três publicações. A análise mostrou que as questões de voz e de saúde vocal são pouco investigadas; e que não há estudos a respeitodo uso vocal profissional, cuidados, saúde, trabalho e qualidade de vida de tradutores e/ou intérpretes. A voz, abordada pela vertente da expressividade, foi considerada importante recurso na interação, mediação, significação e construção de sentidos na interpretação. A questão da vozmerece atenção na formação do Tradutor e Intérprete e no campo educacional; e demanda estudos de perspectiva ampliada, integrada e interdisciplinar (Letras/Tradução e Interpretação, Pedagogia, Linguística, Fonoaudiologia, Saúde do Trabalhador, Saúde Coletiva).

Palavras-chave: Tradução e Interpretação.Educação.Letras. Voz. Fonoaudiologia; Formação de Professores.

\begin{abstract}
Oral translators and interpreters needs a good quality of voice in his wok; and his hights demands of professional voice uses requires attention and cares. The purpose of this article is to understand what the literature states about the voice of oral translator and interpreting. Thus, a systematic review of literature was conducted, by online searches of Speech-Language Pathology and Audiology congress proceedings as well as on the following databases were conducted: Lilacs, Scielo, DOAJ, Medline, ScienceDirect, SpringerLink and Wiley Online Library. The selection involved criteria and process of inclusions and exclusions and results in three publications. The analysisshows that the questions about voice and vocal health are not often investigated; and that there are no studies about the professional voice use, care, health, work and quality of life of the translators and interpreters. The voice, approached in the lines of expressivity, was considered an important resource in the interaction, mediation, signifying and providing meaning to the interpretation. The voice and vocal healthquestion deserves attention in the education of the Translators and Interpretings and in educational field; and demands studies in a expanded, integrated and interdisciplinary perspective (Languages: Translation and Interpreting, Teaching, Linguistics, Speech-Language Pathology and Hearing Sciences, Occupational Health, Collective Health).

KeY-WORdS:Translation and InTERpretation. Education. Languages. Voice. Speech-Language and Hearing Sciences; Teacher EDUCATION.
\end{abstract}




\section{INTRODUÇÃO}

O presente artigo focaliza o tradutor e intérprete oral que, aqui, é compreendido como um profissional da voz-ele depende de uma produção vocal e/ou qualidade vocal específica para o desempenho das suas atividades profissionais.

O profissional tradutor e intérprete trabalha com o discurso oral, produzido a partir de discurso original, em outra língua e/ ou língua estrangeira - comumente duas línguas faladas. Ainda que seja mais comum,o processo de tradução e interpretação oral envolver diferentes línguas faladas, é importante observar que o trabalho do tradutor/ intérprete oral também pode envolver uma língua gestual -por exemplo: a Língua Brasileira de Sinais/LIBRAS.

Assim sendo, em função da possibilidade de variação das línguas envolvidas, o processo de tradução/interpretação oral pode ser desenvolvido: de língua oral para oral (ex.: Português/Inglês), de oral para gestual (ex.: Inglês/LIBRAS) e/ou de gestual para oral (ex.: LIBRAS/Português).

Outras formas de variações podem, ainda, ocorrer, decorrentes das condições, dos contextos e do processo de trabalho de tradução/interpretação oral, que impactam determinando ajustes e mudanças nas formas de uso vocal profissional tradutor e intérprete. Uma dessas variações diz respeito ao processo de tradução/interpretação, que pode ser feito de maneira simultânea ou consecutiva. A seguir, serão descritas cada uma dessas maneiras e algumas das variações que elas podem apresentar.

A tradução/interpretação simultânea ocorre no exato instante de fala do falante que origina o discurso, e o profissional pode contar, em seu trabalho, com o apoio de recursos como cabines e equipamentos, como fones de ouvido e microfones; sendo que os ouvintes contam com o apoio de um sistema de recepção, constituído por altofalantembientes ou fones de ouvido individuais. ${ }^{1}$

Também há casos em que a tradução/ interpretação simultânea ocorre em locais que não comportam o uso de cabine; então o tradutor/intérprete é levado a permanecer acomodado em um canto da sala e a trabalhar com um equipamento portátil, que integra um conjunto de microfone e receptores com fones de ouvido sem fio. ${ }^{2}$

Outras situações podem, ainda, ocorrer, quando a tradução/interpretação simultâneaé feita sem que o profissional disponha de equipamentos: ele poderá permanecer acomodado ao lado da pessoa para quem se destina o trabalho de tradução/interpretação e usar a voz de modo a empregar um ajuste vocal de produção de voz sussurrada ou cochichada. Dessa maneira, o tradutor/ intérprete consegue comunicar o seu discurso traduzido com uma intensidade de voz que não venha a atrapalhar o orador/palestrante/conferencista que profere o discurso original, nemincomodar os demais ouvintes que se encontram no mesmo ambiente. ${ }^{2}$

Quando se trata da maneira de tradução/interpretação consecutiva, o profissional permanece no ambiente em silêncio, durante a apresentação do orador que profere o discurso original, enquanto fazas anotações necessárias para o processo de elaboração e de organização da sua versão traduzida/interpretada; ele somente irá apresentar,para as pessoas, o seu discurso traduzido,a partir do momento em que o falante original con- 
cluiu a sua exposição ou realizou algum tipo de intervalo. ${ }^{1}$

O que importa ressaltar, neste artigo, é que, no processo de tradução/interpretação oral, seja nas variações das línguas envolvidas (oral/gestual) ou das maneiras de sua realização (simultânea ou consecutiva), a voz representa um recurso necessário e importante para o tradutor/intérprete oral desenvolver o seu trabalho com qualidade.

Os tradutores/intérpretes dependem da voz para realizar o seu trabalho; a voz é fundamental para o exercício das suas atividades profissionais, e isso permite que eles sejam considerados profissionais da voz; trabalhadores integrantes de uma categoria que faz uso vocal profissional. A voz profissional é a forma de comunicação oral usada pelas pessoas no desempenho de uma dada atividade profissional na qual o uso da voz é fundamental para o exercício da profissão. ${ }^{3}$

$\mathrm{Na}$ identificação das necessidades vocais no trabalho dos profissionais da vozé importante procurar compreender as especificidades que envolvem, tanto a qualidade de voz, como a demanda de uso vocal requerida pelas diferentes profissões e pelos diversos contextos e condições de trabalho. ${ }^{4}$ As demandas vocais profissionais podem predispor a desconfortos e a riscos de alterações vocais e disfonias que produzem comprometimentos da saúde vocal, prejuízos e consequências negativas que repercutem sobre o sujeito, o seu trabalho e a sua qualidade de vida.

Os trabalhadores das categorias de profissionais da voz (e aqui consideramos inclusos os tradutores/intérpretes orais) necessitamde atenção e preparo para o uso vocal profissional e promoção do cuidado e da saúde vocal e geral. A formação lhes deveria oferecer subsídios e propiciar condições que lhes assegurassem orientações, técnicas e cuidados para a qualidade e a saúde no uso da voz no cotidiano laboral ecarreira profissional.

Entretanto, o que se observa é que, nos cursos de graduação em Letras/Tradução e Interpretação, embora a formação inclua conhecimento de estratégias práticas de tradução, geralmente os alunos não recebem informação e preparo suficiente para o desenvolvimento da comunicação oral a fim de apresentarem voz e fala condizentes com as necessidades de adequação, qualidade $\mathrm{e}$ resposta às demandas de resistência vocal para o enfrentamento das longas e estressantes jornadas de trabalho. ${ }^{4}$

Consequente a essa falta de atenção, de cuidado e de preparo na formação; o que se observa é que, decorrente do uso contínuo de voz em condições de restrição de variação de frequência e intensidade por tempos prolongados, $\mathrm{o}$ aspecto tensional durante a comunicação passa a ser um marcador importante da produção da voz dos tradutores/ intérpretes, podendo evoluir para a configuração de quadros de fadiga vocal ocupacional, de disfonia por tensão muscular, ou de lesões de massa benignas nas pregas vocais. ${ }^{4}$ Isso, obviamente, gera desconfortos, sofrimentos, limitações e problemas para o trabalhador em sua vida diária e no desenvolvimento do seu trabalho.

É importante, ainda, considerar que, nos usos que os tradutores/intérpretes orais fazem da voz,explicitam-se, também, demandasde interação, informação, comunicação, diálogo, significações e construções de sentidos vinculados a processos e práticas 
educacionais e formativas daqueles a quem se destina o seu trabalho. Nessa perspectiva, pode-se, aqui, dizer que o trabalho dos tradutores/intérpretes orais se aproxima (e, muitas vezes, se identifica totalmente) com o do educador/professor. Nessa linha, a considerar os estudos que versam sobre os usos da voz nos contextos educacionais, vale lembrar que a qualidade de voz se faz presente e necessária na facilitação de relações interpessoais e nos processos dialógicos e vínculos construídos entre os agentes do processo educativo. ${ }^{3,5}$ Isso agrega valoração à voz profissional no trabalho de tradução/ interpretação.

Os tradutores/intérpretes orais precisam contar com uma voz de qualidade, com sonoridade agradável, aprazível, interessante e flexível. ${ }^{6,7}$ Alguns pré-requisitos vocais são considerados básicos para esses profissionais: qualidade vocal sem desvios importantes, articulação de fala precisa, ausência de regionalismos, frequência média, intensidade constante, modulação tendendo a restrita, fluência organizada, capacidade de interpretação da modulação e das ênfases presentes na língua do falante original, com transposição adequada para a língua dos ouvintes. ${ }^{4}$

Além disso, o tradutor/intérprete oral precisa de uma voz saudável que disponha de resistência vocal que lhe permita enfrentar altas demandas de uso da voz na sua jornada de trabalho. ${ }^{4,6,7}$

É do interesse do presente estudo conhecer a literatura que versa sobre voz e saúde vocal de tradutores/intérpretes orais.

Dessa forma, este artigo tem por objetivo compreender o que a literatura aborda sobre a voz e/ou a saúde vocal do tradutor e intérprete oral.
O estudo é orientado por algumas perguntas: a voz e a saúde vocal do tradutor e intérprete oral têm sido investigadas, especialmente no Brasil? A partir de que enfoque e/ou vertente?

O estudo estabelece diálogos entre educação e saúde e busca contribuir para discussões interdisciplinares das áreas de Letras/Tradução e Interpretação, Pedagogia, Linguística, Fonoaudiologia, Saúde do Trabalhador e Saúde Coletiva.

\section{MÉTOdos}

Tendo em vista compreender o que a literatura aborda sobre a voz do tradutor e intérprete oral, a metodologia empregada é a da revisão sistemática da literatura.

Em um estudo de revisão sistemática, a literatura referente a determinado tema ou questão não é escolhida de forma aleatória; as publicações que venham a integrar a revisão decorrem de um rigoroso processo de seleção, que se encontra pautado em critérios definidos e preestabelecidos, bem como de etapas de aplicação de testes de relevância que implicam em processos de inclusões e de exclusões. ${ }^{8}$

As publicações incluídas, e a ser analisadas no estudo de revisão têm, portanto, a sua seleção validada; de modo que em um estudo deste tipo, a quantidade de publicações envolvidas não é o quesito principal, já que a seleção pode resultar em um maior ou menor número de publicações. ${ }^{8}$

O processo de revisão sistemática envolve as etapas: 1) Definição da pergunta ou questão/problema; 2) Definição de estratégias de busca e seleção (critérios de inclusão/exclusão e desenho dos testes de 
relevância); 3) Busca; 4) Seleção das publicações mediante aplicação dos critérios e Testes; e 5) Análise das publicações selecionadas para revisão. ${ }^{8}$

No tocante à definição da pergunta ou questão/problema, foram algumas as questões/problemas que orientaram a presente pesquisa: a voz e/ou a saúde vocal de profissionais de tradução oral/interpretação simultânea e consecutiva têm sido investigadas (especialmente no Brasil)? A partir de que enfoque e/ou vertente?

Foram definidas as estratégias de busca e seleção, bem como, as condições que correspondem a critérios de inclusão/exclusão. A seguir, foram desenhados os testes de relevância, explicitando-se novos critérios de inclusão e de exclusão (Quadro 1).

$\mathrm{Na}$ sequência, foram realizadas as buscas, de modo on-line, no período de 28 a 30 de outubro de 2014. Elas se valeram de bases de dados e anais de eventos científicos; sendo aceitas publicações em inglês, português e espanhol.

As bases de dados consultadas foram: Literatura Latino-Americana em Ciências da Saúde (Lilacs), Scientific Electronic Library Online (Scielo), Directory of Open Access Journals (DOAJ), Medical Literature Analysis and Retrieval System Online (MEDLINE), ScienceDirect (Elsevier), SpringerLink, Wiley Online Library.

Também foram consultados os anais de congressos da Sociedade Brasileira de Fonoaudiologia (SBFa: http://www.sbfa. org.br/portal/) e da Associação Brasileira de Pesquisadores em Tradução (ABRAPT: http://abrapt.wordpress.com/).
No momento das buscas, não foi delimitado um período de publicação para o levantamento inicial. Entretanto, cabe ressaltar que, no caso dos anais dos congressos da $\mathrm{SBFa}$, só se encontravam disponíveis, para acesso on-line, os documentos dos eventos ocorridos entre os anos de 2008 e 2013.

As buscas se deram a partir do emprego dos seguintes descritores: voz (voice); saúde vocal (vocal health); higiene vocal (vocal hygiene); disfonia (dysphonia); com uso da expressão booleanas AND intérprete (interpreter); interpretação simultânea $\mathrm{e}$ consecutiva (simultaneous consecutive interpretation); tradução oral (oral translation); tradução e interpretação(translation and interpreting; translation and interpretation ou translating and interpreting). Observação: toda vez que possível foi empregada a técnica de truncamento de palavras: $\operatorname{tradu}\left({ }^{*}\right)$, $\operatorname{interpret}\left({ }^{*}\right)$ e $\operatorname{translat}\left({ }^{*}\right)$.

Uma leitura dos títulos das publicações possibilitou identificar aquelas que se aproximavam e as que se distanciavam do escopo do estudo - sendo excluídas as últimas. Também foram excluídas as publicações duplicadas.

Foi então realizado o trabalho de leitura dos títulos e resumos dos estudos selecionados, por dois revisores, de forma independente e com emprego dos formulários dos testes de relevância I e II, obedecendo aos critérios neles previamente estabelecidos,de inclusão e de exclusão (Quadro 1). Discordâncias foram resolvidas por consenso entre os revisores e, quando o título e/ou resumo não eram esclarecedores, foramacessados os artigos na íntegra. 
Quadro 1-Formulários de aplicação dos testes de relevância I e II

\begin{tabular}{|c|c|}
\hline \multicolumn{2}{|l|}{ FORMULÁRIO DE APLICAÇÃO DO TESTE DE RELEVÂNCIA I } \\
\hline Critérios de inclusão & Não \\
\hline $\begin{array}{l}\text { A publicação aborda aspectos que se relacionam ao trabalho do profissional } \\
\text { de tradução oral/interpretação simultânea e/ou consecutiva? }\end{array}$ & \\
\hline $\begin{array}{l}\text { A publicação aborda aspectos que se relacionam com a saúde do profissional } \\
\text { de tradução oral/interpretação simultânea e/ou consecutiva? }\end{array}$ & \\
\hline $\begin{array}{l}\text { 3. A publicação aborda processos comunicativos e/ou expressivos do } \\
\text { profissional de tradução oral/interpretação simultânea e/ou consecutiva? }\end{array}$ & \\
\hline Critérios de exclusão & \\
\hline 1. É editorial, carta, revisão, dissertação ou tese? & \\
\hline 2. A publicação trata de outro profissional que não o tradutor e intérprete & \\
\hline 3. A publicação trata de tradução textual escrita (e não oral) & \\
\hline FORMULÁRIO DE APLICAÇÃO DO TESTE DE RELEVÂNCIA II & \\
\hline Critérios de inclusão & Não \\
\hline $\begin{array}{l}\text { 1. A publicação aborda temas/questões/aspectos que apresentam relação com } \\
\text { o uso profissional da voz do tradutor oral/intérprete? }\end{array}$ & \\
\hline $\begin{array}{l}\text { 2. A publicação aborda temas/questões/aspectos que apresentam relação com } \\
\text { treinamento e/ou assessoria fonoaudiológica para o profissional de tradu- } \\
\text { ção oral/interpretação simultânea e/ou consecutiva? }\end{array}$ & \\
\hline Critérios de exclusão & \\
\hline $\begin{array}{l}\text { 1. Os temas/questões/aspectos abordados não apresentam relação com os } \\
\text { processos comunicativos orais, expressividade, usos da voz e/ou saúde } \\
\text { vocal. }\end{array}$ & \\
\hline
\end{tabular}

\section{Resultados}

A primeira etapa da busca resultou em um total de 77 estudos, assim distribuídos: Lilacs $(n=32)$, DOAJ $(n=17)$, Medline $(n=7)$, Scielo $(n=4)$, Wiley Online Library $(n=3)$, Springer Link $(n=1)$, Anais/SBFa $(n=11)$ e Anais/Abrapt $(n=2)$.Foram excluídos 28 estudos duplicados, resultando em 49 publicações elegíveis para a leitura dos resumos e aplicação do teste de relevância I.

Após a aplicação do teste de relevância I foram excluídas 26 publicações e aceitas 23 , as quais foram elegíveis para o teste de relevância II.

A partir do teste de relevância II foram excluídas 20 publicações, restando apenas três, as quais preencheram os critérios de aprovação e de validação, sendo estas as publicações que vieram a compor a análise da Revisão Sistemática. 


\section{A Figura 1 (Fluxograma) sintetiza esse processo.}

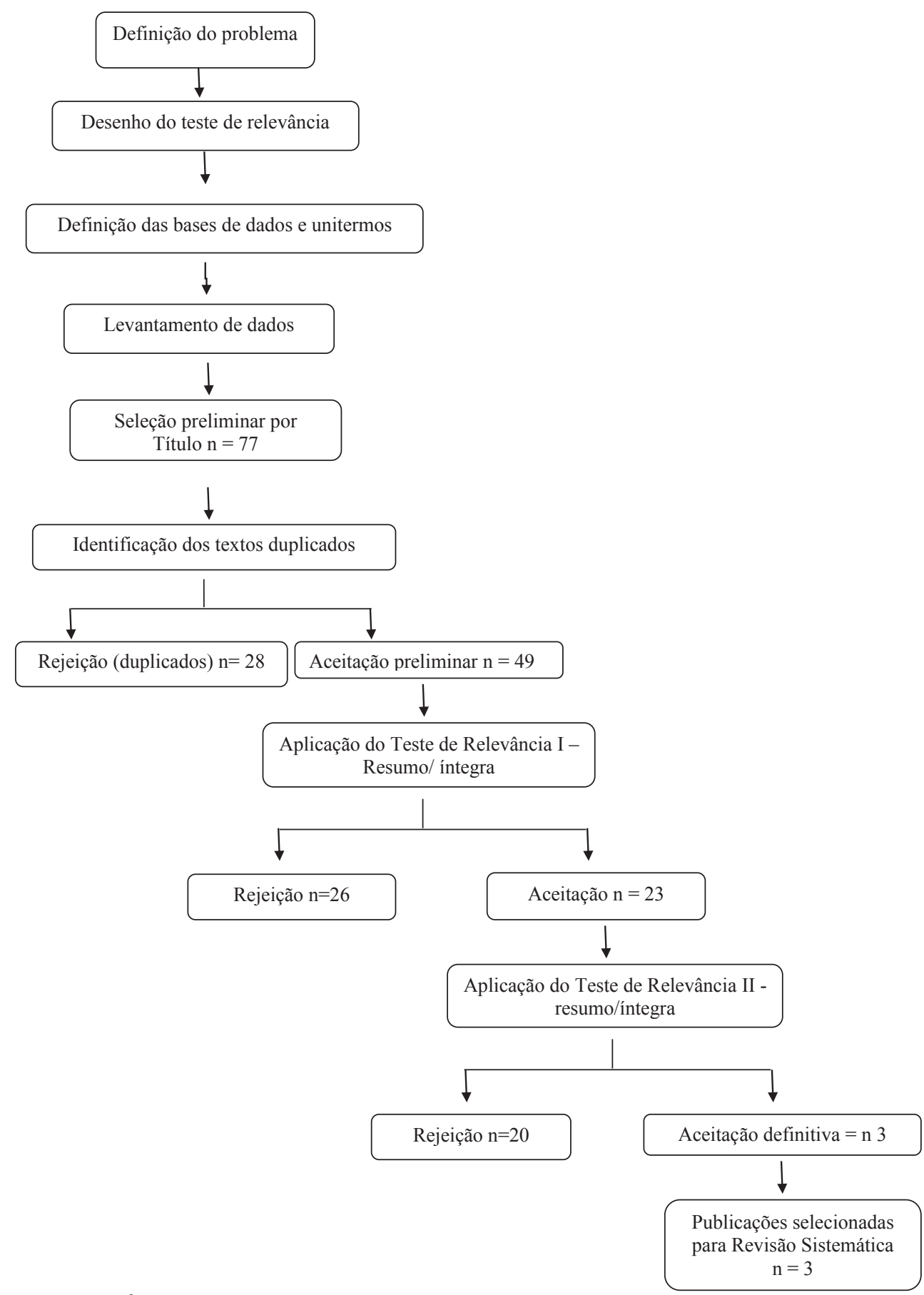

Figura 1 - Fluxograma 
As três publicações selecionadas foram, novamente, submetidas a leituras e os seus dados organizados, sintetizados, classificados nos Quadros 2 e 3.

Quadro 2-Distribuição e caracterização das publicações, segundo autores e título das obras; ano e forma de publicação; estado de procedência do estudo; e área de formação dos autores.

\begin{tabular}{|c|c|c|c|}
\hline Autor/título & $\begin{array}{c}\text { Ano e } \\
\text { publicação }\end{array}$ & Procedência & $\begin{array}{c}\text { Área de formação } \\
\text { do autor }\end{array}$ \\
\hline $\begin{array}{c}\text { OLIVEIRA/2008 } \\
\text { "Como definir limites de evolução em voz } \\
\text { profissional?" }\end{array}$ & $\begin{array}{c}\text { Resumo } \\
\text { Anais/SBFa }\end{array}$ & SP & Fonoaudiologia \\
\hline $\begin{array}{c}\text { ALBRES/2010 } \\
\text { "Mesclagem de voz e tipos de discursos } \\
\text { no processo de interpretação da Língua de } \\
\text { Sinais para o Português oral” }\end{array}$ & $\begin{array}{c}2010 \\
\text { Periódico }\end{array}$ & SP & $\begin{array}{c}\text { Fonoaudiologia } \\
\text { Pedagogia }\end{array}$ \\
\hline $\begin{array}{c}\text { NASCIMENTO/2012 } \\
\text { "Interpretação de LIBRAS para } \\
\text { o português na modalidade oral: } \\
\text { considerações dialógicas" }\end{array}$ & $\begin{array}{c}2012 \\
\text { Periódico }\end{array}$ & SP & $\begin{array}{c}\text { Fonoaudiologia } \\
\text { Linguística } \\
\text { Aplicada a Estudos } \\
\text { da Linguagem }\end{array}$ \\
\hline
\end{tabular}

\section{DISCUSSÃo}

Os resultados do fluxograma e dos Quadros 2 e 3 mostram que a questão da voz de profissionais de tradução/interpretação oral tem sido pouco investigada.

O Quadro 2 mostra que os autores não se repetem; e que não houve mais do que uma publicação, por autor.

Quando se observa a formação inicial dos autores (graduação), prevaleceu a área de Fonoaudiologia, com 100\%. A Fonoaudiologia se volta, entre outras coisas, para a pesquisa, prevenção, avaliação, terapia, aperfeiçoamento e assessoria em comunicação oral e voz profissional; o que torna compreensível tal prevalência.

No entanto, é importante observar que há falta de estudos que se pautem pela ótica de pesquisadores da área de Tradução e Interpretação. - Não há, entre as publicações da revisão, autores com formação inicial em Tradução e Interpretação.

Quando se trata de focalizar as publicações que versam sobre o profissional tradutor/intérprete, o que se observa é que o número de estudos fica ainda mais restrito: apenas duas obras focalizam diretamente esse profissional. - Ressalta-se, aqui, que a obra de Oliveira ${ }^{9}$ aborda profissionais da voz em geral e, embora não cite diretamente o tradutor/intérprete, também não o exclui.

Cabe ressaltar que, nas duas publicações que envolvem diretamente o profissional tradutor/intérprete ${ }^{10,11}$ (Quadro 2),os autores fonoaudiólogos tiveram formação complementar no campo das ciências $\mathrm{Hu}$ manas- especificamente nas áreas de Pe- 
Quadro 3-Distribuição ecaracterização das publicações, segundo autor e ano; sujeitos envolvidos; estratégia empregada no estudo; temáticas e conteúdos abordados; e resultados obtidos.

\begin{tabular}{|c|c|c|c|c|}
\hline $\begin{array}{l}\text { Autor/ } \\
\text { ano }\end{array}$ & Sujeitos & Estratégia & $\begin{array}{l}\text { Temáticas e } \\
\text { conteúdos }\end{array}$ & Resultados \\
\hline $\begin{array}{l}\text { OLIVEIRA } \\
2008\end{array}$ & $\begin{array}{c}\text { profissionais } \\
\text { da voz }\end{array}$ & $\begin{array}{l}\text { teórico/ } \\
\text { reflexivo }\end{array}$ & $\begin{array}{c}\text { queixas vocais, } \\
\text { percepção da } \\
\text { voz, } \\
\text { condições e } \\
\text { demandas de uso } \\
\text { da voz }\end{array}$ & $\begin{array}{l}\text { Aponta aspectos a serem } \\
\text { considerados na definição } \\
\text { dos limites de evolução do } \\
\text { trabalho fonoaudiológico em } \\
\text { voz profissional. }\end{array}$ \\
\hline $\begin{array}{c}\text { ALBRES } \\
2010\end{array}$ & $\begin{array}{l}\text { acadêmica } \\
\text { surda } \\
\text { e } \\
\text { intérprete } \\
\text { LIBRAS } \\
\text { Português }\end{array}$ & $\begin{array}{c}\text { análise de } \\
\text { discursos e } \\
\text { expressividade } \\
\text { da acadêmica } \\
\text { surda e do } \\
\text { intérprete de } \\
\text { LIBRAS. } \\
\text { Mesa redonda }\end{array}$ & $\begin{array}{c}\text { Tipos de } \\
\text { discurso } \\
\text { Mesclagem de } \\
\text { voz } \\
\text { Adaptações e } \\
\text { variações vocais }\end{array}$ & $\begin{array}{l}\text { Acadêmica surda: emprego } \\
\text { de discursos narrativo, } \\
\text { direto e argumentativo, com } \\
\text { sobreposição de fala e "espaço } \\
\text { sub-rogado". } \\
\text { Intérprete: discurso direto, } \\
\text { em primeira pessoa; realiza } \\
\text { adaptações do teor do } \\
\text { discurso; emprega voz enfática } \\
\text { para traduzir sinais "tensos"; } \\
\text { realiza mudanças vocais para } \\
\text { cada personagem e também } \\
\text { na apresentação de novo } \\
\text { emissor. } \\
\text { Conclui que o intérprete } \\
\text { de LIBRAS precisa de } \\
\text { formação quanto ao uso vocal } \\
\text { profissional. }\end{array}$ \\
\hline $\begin{array}{l}\text { NASCIMENTO } \\
2012\end{array}$ & $\begin{array}{c}\text { Alunos de } \\
\text { Tradução e } \\
\text { Interpretação } \\
\text { LIBRAS } \\
\text { Português }\end{array}$ & $\begin{array}{l}\text { Vídeo: locutor } \\
\text { surdo. Exercício } \\
\text { de Tradução e } \\
\text { Interpretação } \\
\text { LIBRAS } \\
\text { Português. }\end{array}$ & $\begin{array}{c}\text { Voz } \\
\text { Expressividade } \\
\text { Produção de } \\
\text { sentidos na } \\
\text { Tradução e } \\
\text { Interpretação } \\
\text { LIBRAS/ } \\
\text { Português }\end{array}$ & $\begin{array}{l}\text { No processo de tradução, } \\
\text { houve distanciamento } \\
\text { entre escolhas linguístico- } \\
\text { composicionais, com quebras } \\
\text { de sentidos. } \\
\text { O processo de interpretação } \\
\text { LIBRAS/Português envolve } \\
\text { exploração de recursos vocais, } \\
\text { da articulação e da prosódia. } \\
\text { Conclui que a voz e a } \\
\text { expressividade oral merecem } \\
\text { destaque como elementos } \\
\text { constitutivos da produção } \\
\text { de sentidos no processo de } \\
\text { tradução/interpretação. }\end{array}$ \\
\hline
\end{tabular}


dagogia e de Linguística. Isso pode indicar que a questão da voz de tradutores/intérpretes passa desapercebida quando se trata de considerar, isoladamente, cada uma das áreas; a problemática da voz/saúde vocal de tradutores/intérpretes demanda enfoque interdisciplinar e somente vem sendo notada e investigada por alguns pesquisadores que transitam pelos campos da saúde e da educação e habitam as interfaces dessas áreas.

No tocante à temporalidade, foi possível observar que as publicações ocorreram em período recente (2008 a 2012); que não houve mais do que uma publicação por ano; e que há anos com ausência de publicações. A partir de 2013, não houve publicações envolvendo a temática em questão.

Quanto à forma de publicação, prevalecem os periódicos (66\%) da área de Tradução e Interpretação.

A publicação em periódicos é positiva; uma vez que essa prática é incentivada pelas agências de incentivo, fomento e amparo à pesquisa;sendo também uma prática valorizada pelos órgãos e entidades governamentais de Educação que avaliam cursos de formação profissional. Também é importante considerar que os textos publicados em periódicos são mais completos e detalhados do que os de anais de eventos; e que, geralmente, as produções publicadas em periódicos foram submetidas a um rigoroso processo de avaliação balizado por critérios de qualidade.

Quanto à procedência dos estudos, é possível notar que os autores estão vinculados a instituições educacionais brasileiras, do Estado de São Paulo. Considerando que o Brasil é um país com contrastes e realidades distintas, cabe apontar a necessidade de expansão de pesquisas sobre a temática que contemplem as diferentes realidades de trabalho e de atuação profissional do tradutor/intérprete oral, tal como elas se apresentam, nas diferentes regiões do Brasil e em outros países.

Quanto aos sujeitos envolvidos nos estudos publicados, o Quadro 3 permite notar que a primeira publicação envolve os profissionais da voz em geral, sem mencionar categorias específicas. Já asegunda publicação ${ }^{10}$ tem, como sujeitos, uma acadêmica surda e um profissional intérprete de LIBRAS/Português participantes de uma mesa redonda de um evento acadêmico universitário. E a terceira publicação ${ }^{11}$ envolve um aluno de um curso de Tradução e Interpretação LIBRAS/Português, no contexto de realização de exercício didático/pedagógico, em formação inicial.

O Quadro 3 também permite observar que o número de sujeitos da área de tradução/interpretação envolvidos nos estudos que tratam da temática da voz/saúde vocal éextremamente reduzido. E, atente-se: um único estudo ${ }^{10}$ conta com um profissional formado.

Há, portanto, necessidade de investimentos na realização de novos estudos atentos à questão do uso vocal profissional e da saúde vocal de tradutores/intérpretes que envolvam um número expressivo de sujeitos, de modo a permitir a visibilidade da voz nos processos de trabalho de tradução/interpretação oral, levando em conta as diversidades envolvidas nas variações das línguas (oral/gestual), nas maneiras de realização (simultânea ou consecutiva), e amostragens de segmentos do mercado e das condições de trabalho no campo de tradução/interpretação oral no país. 
O Quadro 3 mostra que as publicações analisadas encontram-se ambientadas em contextos distintos: o da clínica de voz fonoaudiológica ${ }^{9}$ e o das relações comunicativas e educativas no qual se desenvolve o processo de tradução/interpretação. ${ }^{10,11}$

No contexto da clínica de voz,a publicação de Oliveira ${ }^{9}$ aborda temas/questões/aspectos referentes às percepções de profissionais sobre sua voz, às condições e demandas de uso vocal profissional, aos processos comunicativos e/ou expressivos relacionados ao trabalho dos profissionais da voz, bem como às queixas, cuidados e saúde vocal. Ressalta-se que todos esses aspectos são aplicáveis aos tradutores/intérpretes, apesar da obra não mencionar diretamente essa categoria.

No contexto das relações comunicativas e educativas no qual se desenvolve o processo de tradução/interpretação, as publicações de Albres ${ }^{10}$ e Nascimento ${ }^{11}$ enfatizam as interações entre sujeitos surdos e intérpretes de LIBRAS/Português e investigam os atos discursivos e interpretativos implicados no trabalho do intérprete.

Temas/questões/aspectos relacionados com tipos de discurso, mesclagem de voz, adaptações e variações vocais são explorados no estudo de Albres. ${ }^{10} \mathrm{E}$, no estudo de Nascimento ${ }^{11}$ emergem os temas/ questões/aspectos atinentes à voz emsua vertente de expressividade e às contribuições da voz para os processos de produções de sentidos e de tradução e interpretação LIBRAS/Português.

Cabe notar que, em ambas as publicações ${ }^{10,11}$ a voz do intérprete é referida como elemento integrante do ato interpretativo, com papel relevante na produção de sentidos do processo de tradução/interpretação oral; elas apresentam elementos conclusivos que realçam a importância da voz no contexto expressivo educacional e afirmam a necessidade de inclusão dessa temática na formação profissional.

Os resultados dos estudos que se referem ao profissional de tradução/interpretação ${ }^{10,11}$ afirmam que a voz e a expressividade oral merecem destaque como elementos constitutivos da produção de sentidos no processo de tradução/interpretação; e que o intérprete de LIBRAS necessita de formação e qualificação quanto ao uso vocal profissional.

$\mathrm{O}$ enfoque e a vertente pelos quais a voz do tradutor/intérprete oral é consideradasão a da expressividade, ${ }^{10,11}$ que se refere à qualidade do que é expressivo, constituinte e indissociável da linguagem e da comunicação humana.

A expressividade engloba recursos verbais, vocais e não-verbais, sendo a Fonoaudiologia a área que tem se dedicado ao trabalho com a expressividade junto a diferentes públicos e categorias profissionais da voz. ${ }^{12}$

Quando se consideram as aproximações e similitudes da prática profissional do tradutor/intérprete com o trabalho docente-no sentido de que ambas as funções implicam no uso da voz em práticas que envolvem a linguagem em processos de mediação, de interação, de comunicação, de diálogo, de produção de sentidos, de aprendizagem, de educação -faz-se pertinente afirmar que, tal como a voz do professor, a voz do tradutor/ intérprete também precisa ser trabalhada no conjunto da expressividade. ${ }^{13}$

No entanto,é preciso ampliar o enfoque das ações fonoaudiológicas junto aos profissionais da voz; uma vez que a Fonoaudiologia desenvolve ações em caráter de assessoria 
em voz profissional há algum tempo; mas é recente o enfoque que atribui destaque para a voz em sua vertente de expressão, ${ }^{2,13}$ e são, ainda, limitadas as experiências de caráter educacional. É preciso que a atenção em relação à voz e ao desenvolvimento da expressividade possa ser dada, também, a partir de um caráter educacional, de modo a compor os currículos formativos dos cursos de graduação e a contribuir para a qualificação da formação inicial dos profissionais da voz.

Cabe observar que isso configura um desafio importante a ser enfrentado pelos cursos de graduação em Letras/Tradução e Interpretação; um desafio similar àquele que se apresenta aos cursos de Pedagogia e Licenciaturas. Infelizmente, a maioria dos cursos de formação de professores não possui, ainda, disciplinas curriculares que contemplem as questões do bem-estar vocal profissional e que configurem espaços sociais que contribuam para a necessária discussão e reflexão acerca da voz e da expressividade nos processos educacionais e na formação do professor como um agente participativo da construção da sua prática profissional e do questionamento das condições de trabalho. ${ }^{2}$

As questões de expressividade e do cuidado, que englobam a discussão da voz/saúde vocal-mas que a ela não se detêm - configuram, ainda, demandas reprimidas, silenciadas, aspectos obscurecidos e intocadosque precisam encontrar espaços de abertura para que venham a ser inseridas e debatidas em contextos curriculares da formação inicial e continuada de professores (e, aqui, destaca-se, também de tradutores/intérpretes).

Outro ponto a ser observado, a partir do Quadro 3, é que os dois processos de trabalho de tradução e interpretação (que serviram de base para o desenvolvimento das duas publicações analisadas no presente estudo de revisão, que envolvem o trabalho do tradutor/intérprete),compreendem as línguas Portuguesa e LIBRAS. Desse modo, cabe notar que não houve estudos envolvendo a prática profissional com outras línguas.

A preocupação com a LIBRAS ocupa lugar de destaque no cenário social e educacional nacional, em conformidade com as tendências e movimentos mundiais pela Educação Inclusiva. Envolvem, assim, um conjunto de ações de caráter político, cultural, social e pedagógico, em defesa da afirmação do direito de todos, de aprender e de participar, sem discriminação, da educação e inclusão social. ${ }^{14,15}$ No Brasil, a transformação dos sistemas educacionais em sistemas educacionais inclusivos encontra fundamentação em direitos garantidos pela Constituição Federal de 1988 e também no paradigma da inclusão e defesa dos direitos humanos, na garantia de oportunidades de acesso e de permanência na escola, com atendimento educacional especializado. ${ }^{15} \mathrm{Nesse}$ sentido, visando ao acesso à escola pelo aluno surdo, o decreto $n^{\circ}$. 5.626/2005 dispõe acerca de determinações, tais como: a inclusão da LIBRAS como disciplina curricular; a formação e a certificação do professor, instrutor e tradutor/intérprete de LIBRAS; o ensino da Língua Portuguesa como segunda língua para alunos surdos; a organização para a educação bilíngue no ensino regular; a obrigatoriedade da disciplina de LIBRAS em cursos de formação de professores e de Educação Especial, Letras, Pedagogia e Fonoaudiologia -sendo optativa nos demais cursos de graduação; bem como, o apoio ao uso e à difusão da LIBRAS. ${ }^{14,15}$ 
Outro aspecto que merece ser observado é que nenhuma das publicações dessa revisão sistemática referiu o emprego da interpretação sussurradaou cochichada -o que, provavelmente, se deu em razão de se tratarem de estudos focados em interpretação nas modalidades oral e gestual, envolvendo a LIBRAS.

Apesar de não ter sido citada nos estudos publicados, a voz sussurrada ou cochichada (fonação whispering - tipo de emissão áfona turbulenta, sendo o sussurro de fraca intensidade e o cochicho de forte intensidade $)^{16}$ merece destaque e discussão, pois é uma condição de uso vocal profissional muito presente no trabalho dos tradutores/ intérpretes.

Estudos das áreas de Fonoaudiologia e Otorrinolaringologia que se valeram de investigação eletromiográfica evidenciam que na produção do cochicho há uma interação dos ajustes glóticos e supraglóticos da laringe atuantes nas coordenações do músculo cricoaritenoídeo posterior (que contribui para a abdução glótica) e do músculo tireofaríngeo (que contribui para a constrição supraglótica); sendo que a contração do último é duas vezes maiore mais acentuada, no cochicho, em forte intensidade; que no sussurro, em fraca intensidade.Durante a fonação whispering,os ventrículos laríngeos se estreitam e as estruturas supraglóticas (particularmente as pregas vestibulares) descem e colidem com as pregas vocais, impedindo-as em sua vibração adequada. O fechamento glótico torna-se incompleto, e se configura uma fenda posterior. Além disso, estudos aerodinâmicos na laringe indicam velocidade de fluxo duas vezes maior no sussurro e três vezes maior no cochicho, em relação à fonação usual. ${ }^{16}$
No ato de falar cochichado ou sussurrado há, portanto, um jogo de forças musculares contrárias que resultam em um esforço maior para a produção vocal, com desgaste com o uso vocal prolongado. Ocorrem impedimentos para a vibração livre e fechamento incompleto das pregas vocais, com aproximação intensa da região anterior da porção membranosa das pregas vocais, que acarretam atrito na região nobre de vibração; e afastamento no terço posterior. ${ }^{16-18}$

O emprego do ajuste fonatório em voz sussurrada ou cochichada pode, assim, gerar intensa demanda vocal e representar condição de risco para alterações de voz, fendas glóticas médio-posterior, fonotraumas e disfonias; devendo, portanto, ser evitado em contextos de usos cotidianos e profissional da voz, como parte dos cuidados com a voz e a saúde vocal. ${ }^{16-20}$

No contexto da prática clínica-terapêutica fonoaudiológica das disfonias o emprego do ajuste fonatório da voz sussurrada ou cochichada deve se dar somente mediante acompanhamento e orientação fonoaudiológica. ${ }^{16-18}$ Desse modo, a técnica da voz sussurrada pode ser aplicada em terapias vocais para casos de fendas glóticas das regiões anterior e medial das pregas vocais; ${ }^{18}$ enquanto que a técnica da voz cochichada pode ser empregada como exercício em casos de paresia laríngea e fenda fusiforme anterior, forçando o fechamento glótico anterior da prega vocal com o auxílio da musculatura extrínseca. ${ }^{16}$

$\mathrm{Na}$ área de tradução e interpretação, algumas orientações são dadas no sentido de os tradutores/intérpretes evitarem a interpretação sussurrada ou empregarem a téc- 
nica somente em situações de reuniões rápidas e/ou sob revezamento profissional. ${ }^{1,21}$

É importante destacar que esse aspecto específico das demandas de uso vocal profissional dos tradutores e intérpretes contribui para justificar a necessidade de uma disciplina voltada para o desenvolvimento da expressividade e a formação de uma cultura do cuidado e da saúde no contexto educacional e formativo desses profissionais.

Cabe, ainda, sinalizar a necessidade de estudos acerca dos efeitos do uso vocal profissional na saúde vocal de tradutores e intérpretes (principalmente aqueles que fazem uso da voz cochichada ou sussurrada), atentos a aspectos como: condições de uso, queixas, desconfortos, sinais e sintomas vocais e outros.

Entretanto, vale lembrar que a problemática da saúde vocal e geral dos tradutores e intérpretes não se restringe à questão do uso da voz sussurrada ou cochichada. A atenção, a preocupação e os cuidados com a voz e a saúde vocal e geral são fundamentais na prevenção de disfonias e promoção da saúde em sujeitos que usam a voz profissionalmente. ${ }^{19,20,22-24}$

Porém, não foi identificada, nosdois artigos da revisão sistemática, qualquer menção aos hábitos, cuidados, bem-estar e saúde vocal ou geral do profissional Tradutor e/ou Intérprete.

Sabe-se que a preocupação com a saúde vocal não integra a cultura da maioria dos brasileiros; ${ }^{24}$ no entanto, as ações educacionais voltadas para o cuidado, a saúde e a qualidade de vida no trabalho são indispensáveis na formação profissional. ${ }^{3}$ A temática do cuidado precisa passar a integrar os currículos formativos das categorias que fazem uso vocal profissional, no sentido de uma construção cultural.

Para isso, há que se realizar pesquisas e publicações atentas aos usos e cuidados com a voz profissional e a saúde em geral, no contexto profissional do tradutor/intérprete que possam subsidiar as novas práticas, orientadas por uma cultura do cuidado e da promoção da saúde no trabalho.

As publicações da presente revisão, tampouco, mencionam aspectos referentes aos contextos de ambiente, condições e organização do trabalho do tradutor/intérprete oral. São encontrados, na área de tradução literária, alguns estudos ${ }^{25}$ que abordam as mudançasque envolvem aspectos tecnológicos e das condições de trabalho dos tradutores, ocorridas nas últimas décadas, com efeitos como: a respeitabilidade dos estudos de tradução,pela academia;as questões que envolvem produção, remuneração, direitos autorais e relações com as editoras; a qualidade da tradução e a percepção de uma obra pelo público epela crítica; a vendagem de livros e outros. Mas não há estudos, nessa linha, com tradutores/intérpretes orais.

Possivelmente um dos fatores que dificultam avançar na discussão das problemáticas das condições de trabalho dos tradutores/ intérpretes orais é o fato de que a categoria não possui, ainda, uma norma regulamentadora da profissão nem um Código de Ética regulamentado. ${ }^{26}$ No Brasil, os tradutores e intérpretes da Língua Brasileira de Sinais têm a profissão normatizada pela lei $\mathrm{n}^{\circ}$. 12.319, de 1/9/2010; documento que dispõe sobre aspectos como: valores éticos, respeito à pessoa humana e à cultura do sujeito surdo, sigilo da informação, fidelidade no conteúdo a ser traduzido e profissionalismo ${ }^{27}$ - entre- 
tantoo documento deixa de mencionar aspectos referentes às condições de trabalho $\mathrm{e}$ à proteção à saúde do trabalhador.

As condições de trabalho são importantes e impactam no uso vocal profissional; mas faltam estudos que abordem relações entre voz, trabalho, saúde e qualidade de vida de tradutores e intérpretes orais. Além disso, é preciso compreender que a promoção do bem-estar vocal e da saúde do trabalhador tradutor/intérprete oral não se dará de modo apartado da valorização do profissional e do seu trabalho; e que isso implica em avanços no sentido da profissionalização, a ser discutidos desde a formação inicial.

Encontra-se, aqui, um campo aberto para investigações e diálogos interdisciplinares ambientados, principalmente, na interface das áreas de Educação e Saúde e envolvendo as formações em Pedagogia e as Licenciaturas, Letras/Tradução e Interpretação, Linguística, Fonoaudiologia, Saúde Coletiva, Saúde do Trabalhador e Medicina (especialmente, na especialidade de Ortorrinolaringologia).

\section{CONSIDERAÇões FINAIS}

O presente estudo de revisão mostra que a voz tem sido pouco investigada junto a profissionais tradutores/intérpretes orais, com apenas dois estudos que envolvem as línguasLIBRAS/Português e que abordam a voz pela vertente da expressividade, atribuindo, a ela, valorações positivas: no contexto de tradução/interpretação oral, como elemento integrante do ato interpretativo e da produção de sentidos; e, no contexto educacional dos profissionais, como uma questão a ser discutida e incorporada na formação do tradutor/intérprete.

O estudo de revisão mostra que há um campo aberto para estudos pautados por uma perspectiva ampliada, integrada e interdisciplinar, que abordem relações entre condições de trabalho e as questões de voz, expressividade, cuidado, saúde e qualidade de vida de tradutores/intérpretes orais (o que pode ser extensivo à formação de professores); a ser desenvolvidos nos espaços sociais de formação inicial e continuada e também nos espaços de trabalho.

$O$ desafio maior a ser enfrentado, entretanto, aparenta o de inaugurar espaços curriculares, nos contextos formativos de tradutores e intérpretes e também no Ensino Superior, na graduação em Letras/Tradução e Interpretação, para a necessária discussão dessas questões articuladas às condições e às demandas de trabalho, nas perspectivas de melhoria da qualidade do ato de tradução/interpretação e de valorização do trabalhador e da sua profissão.

\section{REFERÊNCIAS}

1. Aiic. Tipos de interpretação. Associação internacional de intérpretes de conferência. 2012. Disponível em: <http://www.aiicbrasil.com.br/interpretacao.htm>. Acesso em: 16 set. 2014.

2. Carvalho UW. Como ser tradutor e intérprete, 2007. Disponível em: <http://www.teclasap. com.br/como-ser-tradutor-e-interprete/> Acesso em: 5 jun. 2015.

3. Fantini LA, Ferreira LP, Trenche MCB. O bem-estar vocal na formação de professores. Distúrb Comun, 2011; 23(2): 217-226. 
4. Behlau M., Feijó D., Madazio G., Rehder MI, Azevedo R., Ferreira AE. Voz Profissional: Aspectos Gerais e Atuação Fonoaudiológica. In:Behlau M. Voz: o livro do especialista. Vol. II. Rio de Janeiro: Revinter 2005. Reimpressão 2010, p. 287-407.

5. Servilha EAM, Monteiro APS. Estratégias para obter a atenção discente no contexto universitário: o papel da voz do professor. Distúrb Comum. 2007;19(2):225-235.

6. Khaimovich ML,Makarova VN,Kirikova GA. The effect of increased voice and psychophysiological loads on the health status of interpreter guides.Med Tr Prom Ekol. 1995; 11:24-6.

7. Gudgeon A. Voice coaching for interpreters. International Association of Conference Interpreters,2009. Disponível em: <http://aiic.net/issues/284/2008/winter-2009-48> Acesso: $7 / 2 / 2014$.

8. Sampaio RF, Mancini MC. Estudos de revisão sistemática: um guia para síntese criteriosa da evidência científica. Rev. Bras. Fisioterapia 2007; 11(1):83-89.

9. Oliveira IB. Como definir limites de evolução em voz profissional? In: $16^{\circ}$. Congresso Brasileiro de Fonoaudiologia, 2008, São Paulo. Disponível em: <http://www.sbfa.org.br/portal/ anais2008/anais_select.php?op=MR\&cid=277> Acesso em: 28/10/2014.

10. Albres NA. Mesclagem de voz e tipos de discursos no processo de interpretação da língua de sinais para o português oral. Cadernos de Tradução (UFSC). Santa Catarina, v. 2, n. 26, p. 291-306, 2010.

11. Nascimento V. Interpretação Libras para Português na modalidade oral: considerações dialógicas. Tradução \&Comunicação: Rev. Bras. Tradutores, 2012; 24:79-94.

12. Kyrillos LR (Org.). Expressividade: da teoria à prática. Rio de Janeiro: Revinter, 2005.

13. Ferreira LP, Dragone MLS, Giannini SPP, Zambon FC. Atuação fonoaudiológica com professores - da voz ocupacional à voz como recurso do trabalho docente. In:Marchesan IQ, Silva HJ, Tomé MC. Tratado das Especialidades em Fonoaudiologia,1. ed. São Paulo: Guanabara Koogan, 2014, p. 250-57.

14. Brasil. Decreto $\mathbf{n}^{\mathbf{0}}$. 5.626, de 22 de dezembro de 2005. Regulamenta a Lei ${ }^{\circ}$. 10.436, de 24 de abril de 2002, que dispõe sobre a Língua Brasileira de Sinais - Libras, e o art. 18 da Lei nº. 10.098, de 19 de dezembro de 2000. Portal da Legislação - Governo Federal.Brasília-DF, 22 dez. 2005. Disponível em: <http://www.planalto.gov.br/ccivil_03/_Ato2004-2006/2005/Decreto/D5626. htm>. Acesso em: 9mar.2015.

15. Sec/Mec. Marcos político-legais da Educação Especial na perspectiva da Educação Inclusiva. Secretaria de Educação Especial; Ministério da Educação. Brasília, 2010.

16. Pinho SMR, Pontes P. Músculos intrínsecos da laringe e dinâmica vocal. São Paulo: Revinter, 2008.

17. Pinho SMR. Fundamentos em Fonoaudiologia: tratando os distúrbios da voz. Rio de Janeiro: Guanabara Koogan, 1998.

18. Behlau M., Gama ACC, Cielo CA. Técnicas Vocais. In: Marchesan IQ, Silva HJ, Tomé MC Tratado das Especialidades em Fonoaudiologia,1. ed. Rio de Janeiro: Guanabara Koogan, 2014, p. 143-144.

19. Zambon F., Behlau M. Bem estar vocal: uma nova perspectiva de cuidar da voz. São Paulo: Simpro/Cev, 2006.

20. Behlau M., Pontes P. Higiene vocal: cuidando da voz, 4.ed. Rio de Janeiro: Revinter, 2009.

21. Phelan M. The Interpreter's Resource.Reino Unido: Multilingual Matters, 2001.

22. Vilkman E. Voice problems at work: a challenge for occupational safety and health arrangement. Folia Phoniatr. Logopaed.2000; 52(1/3):120-125. 
23. Ferreira IP, Latorre MRDO, Giannini SPP, Ghirardi ACAM, Karmann DF, Silva EE, Figueira S. Influence of abusive vocal habits, hydration, mastication, and sleep in the occurrence of vocal symptoms in teachers. J. Voice; v. 24, n. 1, p. 86-92, 2010.

24. Guimarães VC, Viana MADESR, Barbosa MA, Paiva MLF, Tavares JAG, Camargo LA. Cuidados vocais: questão de prevenção e saúde. Ciênc. Saúde Coletiva, 2010; 15(6):2.799-2.803.

25. Britto PH. As condições de trabalho do tradutor. Cad. Tradução 2007; 1(19):193- 204.

26. Sintra. Informações para estudante e professores de tradução e interpretação. Sindicato Nacional dos Tradutores. 2003. Disponível em: <http://www.sintra.org.br/site/index. php? $\mathrm{p}=\mathrm{c} \& \mathrm{id}=37 \& \operatorname{cod} \mathrm{cat}=21>$ Acesso em: 16 set .2014 .

27. Brasil. Lei $\mathbf{n}^{\mathbf{0}} \mathbf{1 2 . 3 1 9}$, de $\mathbf{1}^{\mathbf{0}}$. de setembro de 2010. Regulamenta a profissão de Tradutor e Intérprete da Língua Brasileira de Sinais - LIBRAS. Portal da Legislação - Governo Federal.Brasília-DF, $1^{\circ}$. set. 2010. Disponível em: <http://www.planalto.gov.br/ccivil_03/_Ato2007-2010/2010/ Lei/L12319.htm>Acesso em: 9mar.2015.

DADOS DAS AUTORAS

\section{Regina Zanella Penteado}

Doutora em Saúde Pública pela Universidade de São Paulo. Docente da Universidade Metodista de Piracicaba (UNIMEP), nos cursos da Faculdade de Ciências da Saúde e da Faculdade de Comunicação e Informática. Piracicaba/SP - Brasil. rzpenteado@unimep.br

\section{Marilia Meneghini}

Graduada em Letras - Tradução e Interpretação pela Universidade Metodista de Piracicaba. Professora de Inglês em escolas pública e privada. Piracicaba/SP - Brasil. marilia meneghini@hotmail.com

Submetido em:23-9-2016

Aceito em: 25-4-2017 